Cilt / Volume 3, Sayı / Issue 3, 2020, pp. 179-188

E - ISSN: 2636-7718

URL: https://journals.gen.tr/arts

DOİ: https://doi.org/10.31566/arts.3.013

Araştırma Makalesi / Research Article

\title{
THREE REVOLUTIONARY CHANGES IN REPRESENTATION: THEORETICAL SUMMARIES, PRACTICAL TOOLS, AND VISUAL EXAMPLES VIA KANYON SHOPPING MALL
}

\author{
Seyed Farhad TAYYEBI * \\ * Istanbul Technical University \\ TURKEY e-mail: tayyebi.sf@gmail.com, \\ ORCID: https://orcid.org/0000-0002-0371-9155
}

Received: 01 January 2020; Accepted: 26 June 2020

\begin{abstract}
Although many scholars have discursively explored the evolution of representation in fine art throughout the ages, the revolutionary changes of the term are not well summarized nor illustrated in architecture. This paper, after exploring the radical changes of representation, reflects the revolutions of representation concerning the place of representation in the perception process of art, as well as the method of acquiring the representation both in discourse and practice. Then, a building tangibly illustrates the place of representation in architecture. The study shows representation has experienced three revolutionary interpretations, concentrating on mimesis, experience, and imagination. Each stage penetrates the practice of art via imitation, resemblance, and denotation respectively. Finally, the paper by illustrating the existence of the three modes of representation in Kanyon Shopping Mall, not only provides a better understanding of representation but also shows how applying representation in architecture can enable the users/observers to interact with the building forms and provides opportunity to elevate the perception of a building to a higher aesthetic level of experience.
\end{abstract}

Key Words: Representation; Art; Aesthetic Experience; Architectural Representation; Kanyon Shopping Mall 


\section{INTRODUCTION}

Representation had always been a very critical aspect of art and accordingly a focal point for many theoreticians and philosophers. Despite its historical root which dates back as early as Plato and Aristotle, the coherent relationship between representation and aesthetic experience results in being widely discussed by theoreticians in art, until recent years. Even many philosophers, during the second half of the twentieth century, ascribe the solution of understanding of art to the perception of representation and its effect on aesthetic experience (Kieran and Lopes 2003). In this regard, it is a great curiosity to discover the main characteristics of the term and to explore the way its interpretations interfere in a practice of art. Even though many scholars have discursively explored the evolutionary changes of the term, the very revolutionary theoretical changes, as well as the acquiring methods in practice are not summarized coherently. In addition, the trace of representation is mostly reflected in fine arts, though the term is not limited, and their trace can be visible in the practice of architecture. By concerning these issues, this paper aims to explore the main revolutionary changes of representation to show its theoretical place in the perception process of an art; it also concern the way representation interferes in the practice of art, via visually reflecting its trace in a building as a case study.

In order to discover and summarize the revolution of representation, reviewing literature and theoretical exploration by exhaustive library investigation provide a clear understanding of the flow of changes. Then, concerning the process of and artwork perception, and the place of representation and method of acquiring the representation provide assistive tools to distinguish the main revolutions of the term representation. Finally, the main revolutions are identified. Finally, in order to illustrate the distinguishable revolutions in a more tangible manner, they are demonstrated in a building as a case study.

In this regard, the Kanyon Shopping Mall awarded the Cityscape Architectural Review is selected to tangibly illustrate how the representation exists in an architectural form, as well as to confirm the potential existing behind the representation to make an architectural form more aesthetic in perception. Jerde Partnership and Tabanlioglu Architects design the building as a multifunctional building in 2006 with an area of $30.000 \mathrm{~m}^{2}$. The designer of the project declares the aim of the project as an "Interior streets encircled by courtyards associate all buildings and areas that cause to feel like you are in a compact city" (Tabanlıoglu-Architects 2006). That is to say, the courtyard plays the role of a street at the heart of the project to find yourself in another city. In this regard, the focal point of the project is the courtyard, as the place and main context of representation. The especial form of the building and the courtyard of the project provide a potential to illustrate the revolutionary changes of representation. Thus, this building is selected to tangibly display the trace of representation. Please consider, demonstrating the existence of the representation in the building form does not imply the deliberate action of the architects to acquire the discussed representations, nor confirms that any observer can simply realize the trace of representation. Otherwise, the building is merely selected to vividly reflect and provide a better understanding of the main revolution of representation. 
Figure 1: Left: Kanyon Shopping Mall, Right: Courtyard as Focal Point of the Project,

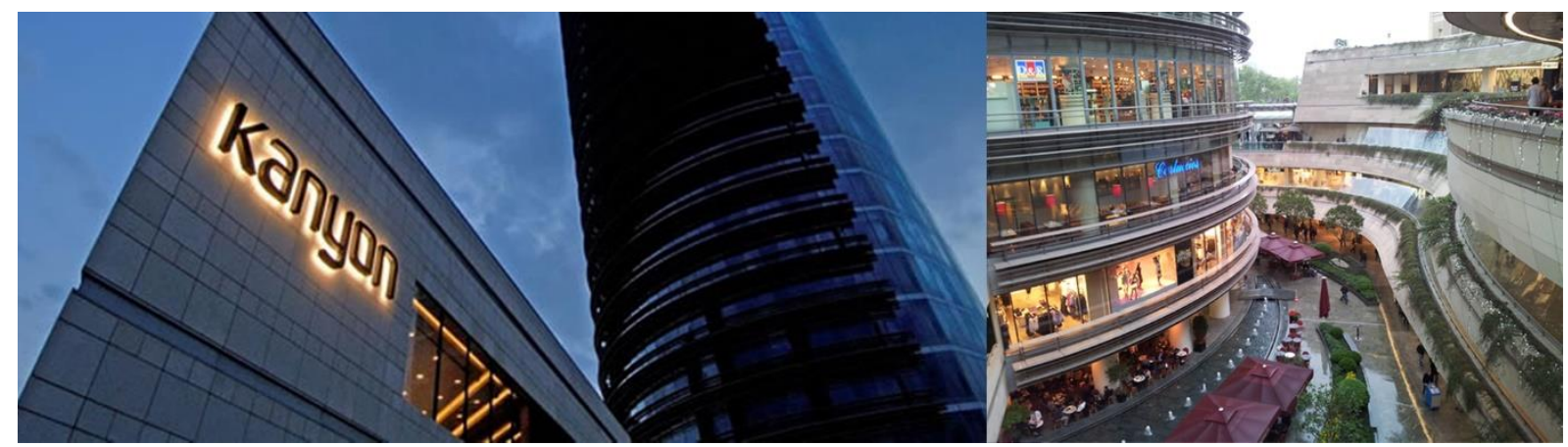

Image Courtesy: Author

The term has experienced three revolutionary advancements in philosophical definition, its place in the perception of art, and its penetrating method into the practice of art. The next three sections reflect each mode of representation orderly. Each section, initially, discusses the philosophical definitions, and its place in the perception process of art via an abstract graph. The graph, not only shows the place and the way representation works in the process of art perception, but also comparing the graphs in the sections gives comprehensive insight on the how the term has changed over the ages. Lastly, the Kanyon Shopping Mall as a case study reflects the place of representation in the practice of architecture.

\section{REPRESENTATION IN MIMESIS AND IMITATION}

Representation is reputedly mentioned as the translation of the word mimesis of the ancient time. Although mimesis has a more limited interpretation, it is considered as the closest word to the philosophically complicated and vague term of representation. As a trace of representation exists in many discussions on art, both Plato and Aristotle agreed that mimesis is a must criterion for an artwork. For them, art is mimetic, though they were ascribing dissimilar definition to mimesis. For Plato and his ancestors, the term mimesis considers as "purely static simulation of appearance"; alike "the wooden effigy of a corpse" which can replicate extremely the feature of its real source (Halliwell 1998:110). Accordingly, in Plato's work mimesis whether or not has a trace of "deception"; the deceptive manner of mimesis is achievable by somehow impersonation in poetry, and a mirror-like image in painting (Rorty 1992:74-78). Thus, mimesis for Plato is "the reproduction of at least some of the qualities of an original" which aims mostly but not necessarily to deceive its audience (Rorty 1992:78).

On the other hand, Aristotle defines mimesis to some degree free of platonic influence (Rorty, 1992, p. 74). For him, mimesis of "O gives us the sort of impression we would have it if we were having an experience of O". That is, affecting and responding to a mimetic simulated object is similar to the first-hand experience (Rorty 1992:93-94). In this regard, Aristotle's definition of mimesis is more likely to be assumed as reproducing something to "make-believe" of the original one (Rorty 1992:90). Although it might have a trace of Plato's deception, to Aristotle, it is more toward the experience of art, rather than the artwork itself; it brings about the catharsis of emotions (Aristotle 1987:48). His opinion is the best explained in the statement "right emotion is felt toward the right object on the right occasion" (Eldridge 2003:42). Consequently, according to Heidegger, mimesis to Aristotle and Plato is generally assumed as "reproduction of a thing's general essence" (Heidegger 1971:37).

Both Plato and Aristotle believe we need to learn which part of the subject is significant in mimesis and how to accomplish it. Aristotle believes mimesis, with its natural essence, arises out of our normal interactions with others and with our environment (Eldridge 2003:40); the 
learning starts from our childhood (Aristotle 1987:4). Every art is related to physical material and needs some techniques to do perfections in execution, something which Matthew Arnold calls it "pure and flawless workmanship." (Dewey 1934:48). For instance "molding of clay, chipping off marble, casting of bronze, laying on of pigment, constructing of buildings, singing of songs, playing of instruments, enacting role on the stage, going through rhythmic movements in the dance" (Dewey 1934:48)are being used in an art production and need exercise. Accordingly, in regards to different contexts, we learn which aspects of things may matter to us; and through the experience, we improve ourselves to do them at an impressive advanced level.

Consequently, both Plato and Aristotle believe the primary concern of mimesis is making a relationship between a subject and an artwork, though the trace of experience and emotion can be seen at the edge of Aristotle's views. There must be a subject which aims to be represented as an artwork; the experience of the deceptive artwork gives us the impression of the subject and results in arising our feeling and emotion. This process is illustrated in figure 2, to reflect the place of mimesis from a classical point of view, as presumably the root of representation in modern times.

Figure 2: Mimesis and Imitation in Classical Process of Art

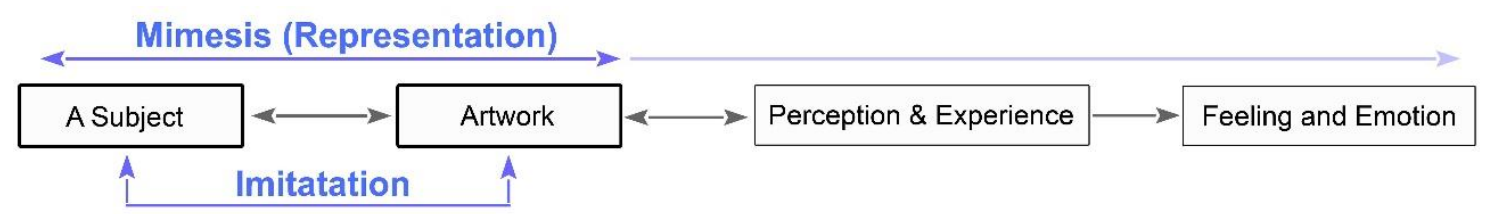

The theoretical term of mimesis comes to practice via imitation. Both Plato and Aristotle concerning visual images (Aristotle 1987) find mimesis the key factor for an artwork in theoretical and more conceptual discussion; otherwise, Aristotle believes works of art are imitations of a subject matter in practice. A successful imitation must have "the power of engaging our attention and our emotions almost as if it were real" (Eldridge 2003:27). A subject needs to be copied or imitated in an artwork, reminding the Goodman quotation: "Art is not a copy of the world. One damn of the damn things is enough." (Goodman 1976:3). Thus, imitation is the physical reproduction of a subject in order to absorb our attention to reach us to the provocation of emotion of mimesis. As figure 2 shows, the place of mimesis and imitation are about the same, while imitation is more related to physical material and practice of art and mimesis covers its effect on experience. Moreover, the mimesis can take place in fiction and internal perception, unlike imitation, which is merely related to physical material and practical features.

In practice, selecting the main subject and imitation methods, like mimesis, are related to the artist's point of view, background, and experiences. To be able to have original imitative art, the subject must be observed by more innocent eyes of artists, though real naïve eyes do not exist indeed. Ernst Gombrich insists, there is no innocent eye since it is "obsessed by its own past and by old and new institutions" (Goodman 1976:8). Kant also declares, "The innocent eye is blind and the virgin mind empty." (Goodman 1976:8). This is the reason why Dewey, Walton, and Danto argue, "we need to know the cultural and political situation and the artistic tradition of work in order to discern what is represented and expressed in it." (Eldridge 2003:142). Interestingly, the more innocent eyes of the artists are the ones that rescue the artists to be saturated by the commonality. This is why artists do their most endeavors to depart themselves from stocking in ordinary routine, to come up with a more naïve perspective. Not only artists' eyes and their ability influence on imitation, the medium of an artwork impacts on 
the imitation complexity level. As Paul Shorey notes, both Plato and Aristotle believe the art of music is the most complex imitative art (Eldridge 2003:29) since imitation is related to structure and tactile material comprising form, which music does not have. In this regard, lack of physical material in some contexts results in the term 'emulation' fits better than imitation (Rorty 1992:90). Consequently, artists are indeed the decision-makers of the imitation method, medium, and accordingly the complexity level.

Against Aristotle and his ancestors, many recent philosophers believe any centrally successful works of art do not present a subject matter at all. For instance, Anne Sheppard notes an abstract painting, like Mondrian's paintings, as well as a piece of music does not represent a subject but emotions (Eldridge 2003:28). Although the necessity of imitation in art is radically questioned, there are still traces of imitation in recent artwork. Imitation which is related to the similar physical feature of the artwork emerges in the form of the Kanyon shopping mall. The central courtyard as the focal point of the project is mainly formed on the basis of Canyon rocks. As Figure 3 shows, similarities between the imitated subject and the artwork recall Plato's quotation "appears as it appears." (Eldridge 2003:31-32). For instance, the horizontal lines of the façade of the Kanyon are clearly connected to the line on the Canyon rocks. Also, the parallel material, color, texture, and shapes are other smaller-scale feature are also identical. The curved plates on the facade and a similar proportion of the place are other factors that assist the success of the imitation. The architect via the imitative character of the courtyard aims to provoke curiosity senses of the people visiting the mall, give the visitors the impression to follow their journey within the mall and finally make the shopping mall more attractive and dynamic. Although, the effect of the imitation on the visitor's experience in practice can be explored in another study, consequently, the trace of imitation as a practical feature of mimesis is visible in the Kanyon Shopping Mall.

Figure 3: Kanyon Shopping Mall as an Imitation of the Canyon Rocks

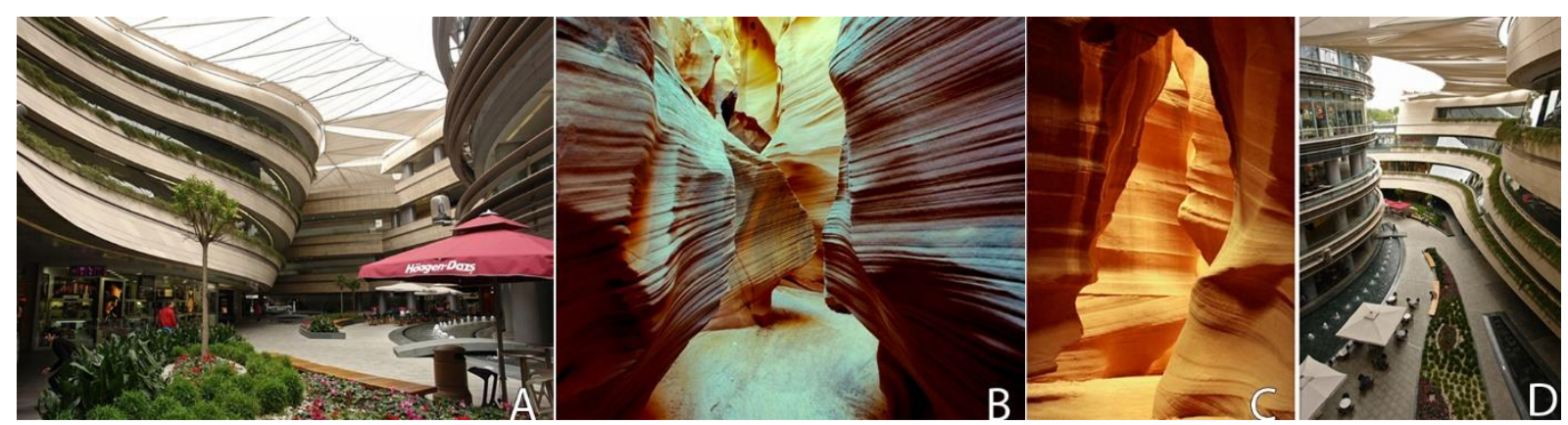

(Dysturb.Net 2008a, 2008b; Fricke 2011)

\section{REPRESENTATION IN EXPERIENCE AND RESEMBLANCE}

The necessity of representation of a subject in an artwork is questioned by many thinkers. For example, Dewey believes it is not necessary to represent a subject in an art (Eldridge 2003). To him, whether there is a subject to be represented or not, we see and experience an artwork; "the actual work of art is what the product does with and in experience." (Dewey 1934:3). By distinguishing between the artwork and the actual work of art, Dewey believes the art product is a vehicle for the artistic experience and the work of art is the vehicle as it is actually experienced, whether there is a subject represented in or not (Eldridge 2003:9). Similarly, Goodman and Beardsley evaluate art based on the ability to produce aesthetic experience which is at the end of the experimental procedure, though Goodman believes works of art are like symbols, referring to things outside itself, and Beardsley claims that aesthetic experience is detached from the references, and then must be evaluated on the basis of non- 
referential aspects (Dickie 1997:152). Thus, artwork is then like a tool for the aesthetic journey of experience resulting in feeling-provocative perception.

The art theory revolutionary shifted toward the experience of an artwork. Accordingly, the concentration of representation turns from the production process toward the experience and perception process. The perception starts with the sensation and will be followed by consciousness exploration of artwork during the experience (Lehrer 2012:32). As Dewey's notes about art, "an experience of thinking about something", is evident in attentive perception of viewers (Dewey 1934:38), they all related more with the effect of the artwork on the viewer's way of thinking. Thus, the intention of art assumed to "set up in an audience a line of thinking about a subject matter" (Eldridge 2003:25) to reach a feeling and emotion (Fig. 4). Accordingly, the place of representation has also shifted from within the artwork, toward within the thoughts of the viewers, which can be in-depth to the extent of reality ignorance. According to Bergson the practical representational response may lead us to ignore the immediate deliverance of consciousness, something he called "ignorance of what reality is like"; that is "the immediate reality of consciousness" (Lehrer 2012:32). Hence, throughout the historical shift toward experience-oriented theories, representation is also displaced to the perception process within the viewers' thoughts, which might be accompanied by ignorance of reality by submerging in thinking and aesthetic experiences.

Figure 4: Experimental perception in an art

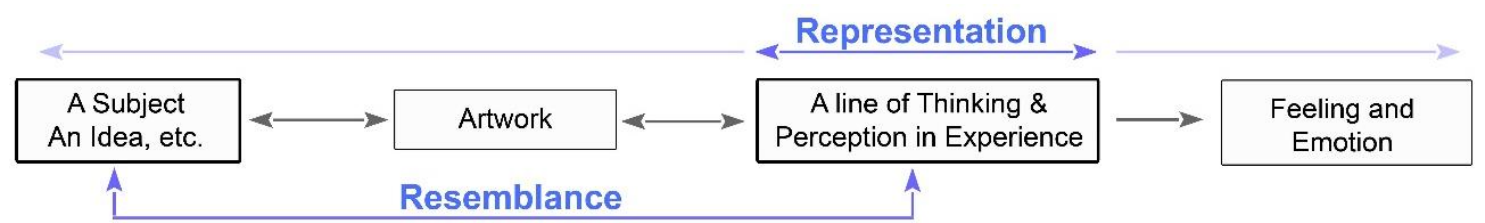

The experience-based definition of art and accordingly shifting the place of representation resulted in the emergence of resemblance, as a practical aspect of representation in this school of thought. As imitation was a practical tool for representation in the ancient definition, resemblance appeared to mold the representation in experience-based definition (compare figure 2 and 4). Both imitation and resemblance are related with the physical appearance and concerned with visual representation. Even though imitation aims to make similar physical appearance in design process, the resemblance deals with similarity in visible representation of a subject or, according to Dewey, an idea in experimental explorative process and internal perception of viewers (fig. 4). Another difference between the imitation and resemblance roots in the method of the visual representation that are predefined/fixed and flexible/changeable respectively. In contrast to just one clear and perfect copy of a subject provided by a fixed method in imitation, resemblance has more flexibility in both method and outcome, especially when it accompanies the "aboutness" theory of Danto, when he plainly expresses "works of art has aboutness" (Eldridge 2003:79). All in all, like mimesis which aims to provide a perfect copy of a subject in an artwork via a fixed method, resemblance with more dynamic and flexible character within varieties of styles aims to provide similar visual experience and reflect the representation in the experience phase of an artwork.

The resemblance is not essential nor adequate in representation; it is like an assistant factor for the aesthetic experience of art. Goodman in his book, The Languages of Art, declares resemblance is obviously "not sufficient for representation" (Goodman 1976:4). He exampled identical twins that may resemble each other, but they do not represent each other. Goldman declares the main criteria relate to the intention of resemblance; as an instance, the twins do not represent each other since there is no intention to create a visual experience in viewers (Eldridge 
2003:33). The intention is a criterion for resemblance. With the aboutness of Danto, even there can be no accurate similarity in the physical feature of an artwork and the source but represent something intentionally. For instance, an actor in a movie may represent and refer to another person when there is just a tiny sign of similarity, even as concise as a hat. The resemblance and similar depiction can effectively assist the viewers of artwork to be experienced as the artist intends. Consequently, resemblance is neither necessary nor sufficient for representation, rather it is like an assistant to have a representative aesthetic experience resulted in being mentioned as a criterion of representation.

Being evolved in experimental exploration, experience should be accompanied for a better perception of a resemblance. Apart from the visual imitation discussed in the previous section, the experience of the Kanyon shopping mall may resemble the experience of the Canyon rocks. Apart from the discussed imitative similarities whether or not influencing the experience of the shopping mall, the high-rise building adjacent to the courtyard can provoke the same feeling, and arise similar experience and mental cognition in experience, despite its narrow phyhsical similarities (fig 5-A). As a Canyon rocks has a gigantic scale and the observers may find themselves too miniature comparing to the atmosphere, the scale of the high-rise building may reflect the same feeling while being experienced by the shopping mall observers. According to Dewey, in the resemblance, the whole is important in the experience not every single part; thus, in resemblance, some parts can be non-referential to the represented idea. In the Kanyon, when continuing the journey to the upper floors, the sphere-like volume has little trace of Canyon imitation in physical features (fig 5-B, C, and D); otherwise, the viewer's though during the experience in general may remain consistent to Canyon. Consequently, apart from the imitation-like similarities assisting the similar perception of the Canyon, the scale of the high-rise building, applying the less-similar physical similarities, and having some non-referential masses, reflects the trace of resemblance and the significance of the general experience of the shopping mall.

Figure 5: Resemblance in the experience of Kanyon Shopping Mall,

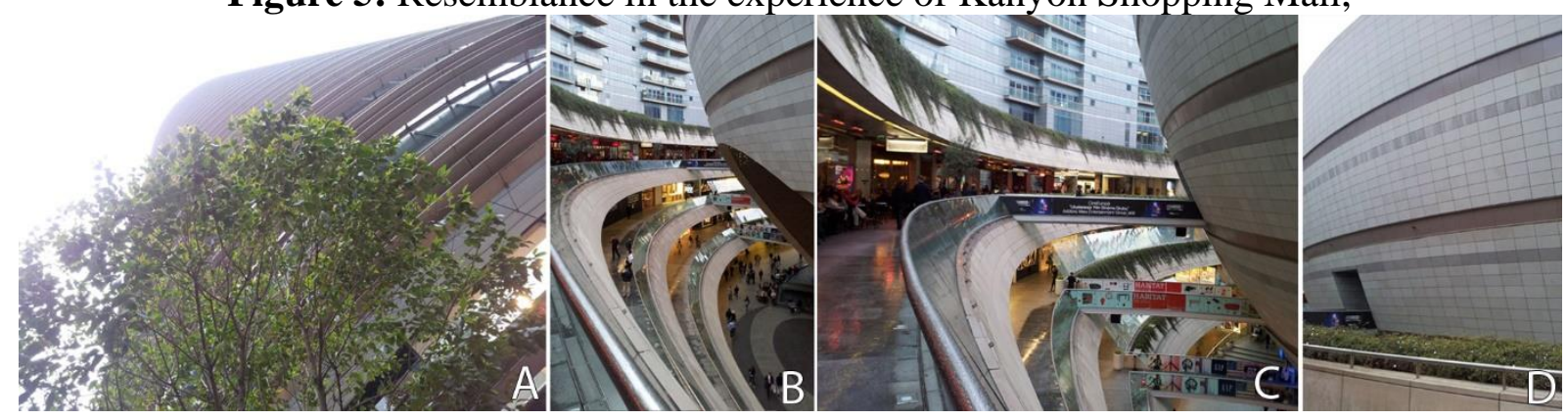

Image Courtesy Author

\section{REPRESENTATION IN IMAGINATION AND DENOTATION}

During the past twenty years, the trace of imagination in perception and art experience has become increasingly significant. Over the history, imagination had been is "a perceptual echo in the mind" (Bates 2012:xxiv); therefore, the physical imitation was the dominant criteria in art, which later on be reflected in the imagination and perception of an artwork. This essentially mimetic-based view of imagination was rejected in the late 1800 s by Kant (Bates 2012), who believes imagination is more than echo of experience in mind. In this sense, the imagination is not a reflective process of our background rather is productive. Furthermore, imagination, as Currie believes, is independent of what is believed or desired (Kieran and Lopes 2003:5), and blossoms freely via fiction and dream. Even the trace of imagination become visible in thinking system; Kant, Hegel, and Dewey placed imagination at the heart of 
rationality and our perceptual system (Bates 2012). All these philosophical evolutions made imagination "a central concept of philosophy of art" (Kieran and Lopes 2003:224); and changed the perception procedure of an artwork and thus the context of representation.

Imagination as a robust mean for human perception and artistic experience has become the context of representation. In accordance with the significance of the imagination, works of art remain, as Dewey puts it, "means by which we enter, through imagination and the emotions they invoke, into other forms of relationship and participation than our own." (Dewey 1934:333). In regards to the focus of the paper on representation, Dewey usefully distinguishes between ordinary representation and artistic representation that are like statement and expression respectively. An intellectual statement is valuable in "the degree in which it conducts the mind" (Dewey 1934:90). On the other hand, an artistic expression, additionally, has an individualized expressive connection between an individual and a particular event (Dewey 1934:90-91). When the representation is specifically artistic, then it will "present things or aspects of things from a [specific] point of view and with an emotional attitude of engagement..." (Eldridge 2003:44). Consequently, imagination is the place of representation triggers by a conductive characteristics of an artwork (fig.6).

Figure 6: Mental Representation through Imagination and Denotation during the Experiencing

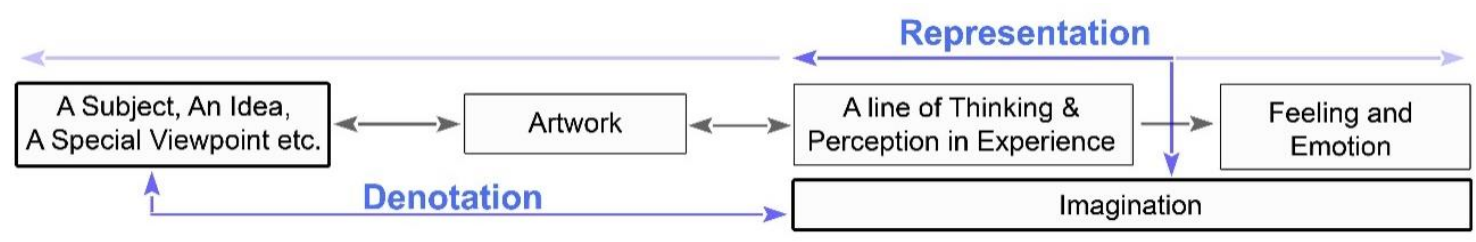

The shift towards the mental representation interrelates in the necessity of the existence of some conducting items for the productive imagination. Imagination forms and grows based on observation and sensory experience. In this regard, there must be some referential sensible items in the artwork in order to lead the imagination towards the perception of the main idea. The references to the main idea of the artist are regarded as denotations. For instance, in an artwork aimed to dedicate the happiness of being in paradise to the viewers, any references like a glorious space saturated with the cheerful signs leading the mind towards the intention of the artist are indeed the denotations. Since the freely productive imagination is the context of representation, it is no necessity an artwork denotes to the ones that exist in the reality or have been already experienced by the viewers; the idea of the artist by the assist of the denotations represented in the productive imagination freely. Goodman believes "denotation is the core of representation" and is also independent of resemblance (Goodman 1976:5); the artwork must be a referential symbol for it. Consequently, as figure 6 shows, the denotations lead the viewer's mind by making a line for their thought and imagination in the explorative experience of an artwork to reach the aimed aesthetic experience.

The denotations as the essential issue in representation exists in the Kanyon shopping mall. The denotations as the signs provoking our productive imagination start from the time when a viewer decides to visit the Kanyon; the name of the project recalls the popular touristic area of the Canyon and evokes our mind towards the experience of the Canyon through the imagination (fig. 7A). Besides, the first view of the Kanyon, a transparent gate between two solid formal volumes, recalls the Canyon and trigger our imagination journey. This sense empowers by the curved opening in the façade which recalls the concave rocks of the Canyon covering the head of visitors, accompanied by the juxtaposition of the stone and water (fig. 7B). Thus, the name and first view of the Kanyon invites you for an imagination journey and mental representation of the Canyon. Then, the visitors have been warmed up enough to curiously 
experience the Canyon through the exploration of the building. The first scene after passing the entrance gates, either from the main street or the metro-line, is the courtyard reflecting the most glorious images of the Canyon rocks, which is accompanied by the unexplainable reverberating sound of the space (fig. 7C). The first scene after the entrance makes all your imaginative dreams of the space true; this shocking valuable experience, directly moves your emotion and feeling. Continuing the journey also repetitively refers and keep your imagination connected to Canyon, despite being at the heart of Istanbul (fig. 7D). Consequently, the assistive denotations lead our dreams and imagination to fulfill the representation of Canyon in our mind and finally reach the aesthetic experience being engaged by the feeling and emotion.

Figure 7: Denotation in the Kanyon Shopping Mall
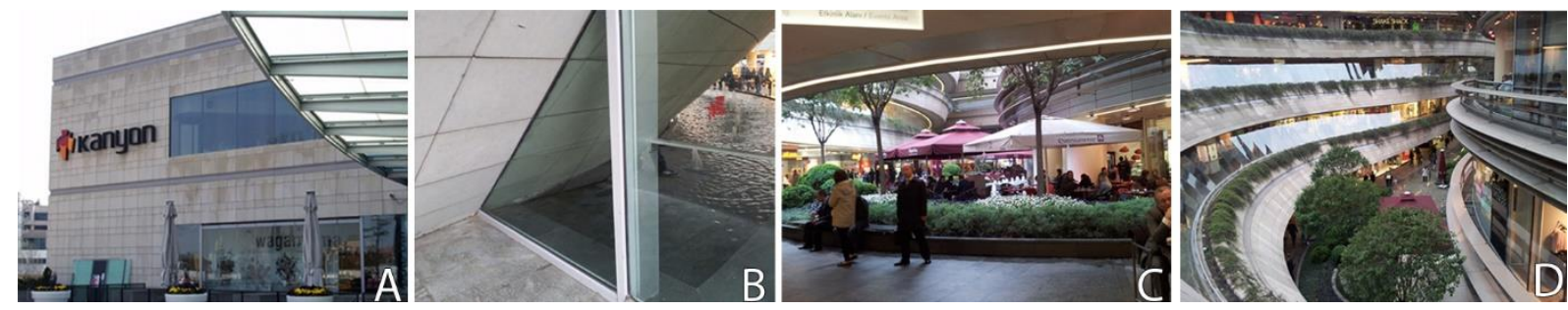

Image Courtesy: Author \& (Nichols 2009)

\section{DISCUSSION AND CONCLUSION}

This study reflects the three theoretical revolutionized interpretations and contexts for representation. It also shows the assistive tools for securing the representation in practice. in addition, the trace of theoretical and practical changes of each revolution is illustrated in the Kanyon Shopping Mall. As discussed, the first term referring to the representation is mimesis coined by Greek philosophers, which is concentrated on accurate reproducing the physical feature of a subject to give the sense of experiencing the original one. Thus, this representation mostly consider the methods and techniques applied during the artwork production. This interpretation comes into the practical realm under the name of imitation. Despite being related to very old centuries, the traces of imitation of Canyon exist in the Kanyon shopping mall by the similar physical features like the curvature of the courtyard volumes, horizontal lines on the internal façade, color and pattern of materials, and etc.

In the following ages, the representation shifts towards the experience process of an artwork and its effects on the viewers. Thus, the viewers' perception became the first goal of an artwork rather than the process of artistic production; instead of having a subject to be fully represented in an artwork, there can be a subject, idea, or a thought to be represented and perceived during the experience of the artwork. This theoretical interpretation comes into practice by the term of resemblance. The Kanyon Shopping Mall as an evident reveals the existence resemblance in the building. The similar feature of the facade, the proportion, and the whole perception of the courtyard as an internal exterior space are the main mentionable resemblance of the building, though the requirement of the experimental exploration is necessarily required in this philosophical revolution of the representation term.

The recent revolution of the definition of the representation turns the sensory experimental-based into the mental imagination. The representation forms in the mind via productive imagination arousing from the explorative perception. The productive imagination triggers with a conductive artwork, coming into practice by denotation. An artwork via some leading denotations toward an idea triggers our productive imaginations toward an aesthetic experience. The denotation as a practical factor of representation is also evidently visible in the Kanyon Shopping Mall. The name of the project, the transparent entrance, curved opening, first 
scene of the shopping mall, and of course, the explorative experiencing has lots of denotation to the Canyon rocks.

Consequently, the representation in art experienced three revolutionary changes over the ages. Each perspective provides a new method to attain the representation in practice, starting from imitation, to resemblance, and finally to denotation. All these three assistive tools in providing representation are presented and discussed via the Kanyon Shopping Mall. This case study not only reflects the place of imitation, resemblance and denotation in the building as an architectural form, but also it shows how it is possible to utilize representation to enable the users' imagination for an aesthetic experience.

\section{REFERENCES}

ARISTOTLE, I., I. 1987. Poetics, Trans. Richard Janko, Indianapolis: Hackett Publishing.

BATES, J.A., 2012, Hegel's Theory of Imagination, Suny Press.

DEWEY, J., 1934, “Art as Experience”, New York: Minton, Balch, and Company.

DICKIE, G., 1997, Introduction to Aesthetics: An Analytic Approach, Vol. 82. Oxford University Press Oxford.

Dysturb.Net. 2008a, “Kanyon Mall Istanbul." Retrieved December 30, 2019 (http://www.flickr.com/photos/7179900@N05/2489702647).

Dysturb.Net. 2008b, “Kanyon Shopping Mall 1." Retrieved December 30, 2019 (https://www.flickr.com/photos/7179900@N05/2489698987).

ELDRIDGE, R., 2003, An Introduction to the Philosophy of Art, Cambridge University Press.

FRICKE, R., 2011, Samsara.

GOODMAN, N., 1976. Languages of Art: An Approach to a Theory of Symbols. Hackett publishing.

HALLIWELL, S., 1998. Aristotle's Poetics, University of Chicago Press.

HEIDEGGER, M., 1971. Poetry, Language, Thought, Trans. Vol. 150.

KIERAN, M., and LOPES, D., 2003, Imagination, Philosophy, and the Arts. Routledge.

LEHRER, Keith., 2012, Art, Self and Knowledge, OUP USA.

NICHOLS, Harvey., 2009, “Kanyon Shopping Center, Istanbul. Apple Store. Wagamama. Harvey Nichols." Retrieved December 30, 2019 (http://www.mobypicture.com/user/amymccl1/view/176281).

RORTY, Amelie Oksenberg, ed. 1992, Essays on Aristotle's Poetics. Princeton University Press.

TABANLIOĞLU-ARCHITECTS, 2006, “Kanyon Project.” Retrieved December 30, 2019 (http://www.tabanlioglu.com/project/kanyon/). 